"If the emphasis for the care of chronic psychotics is to be shifted from the mental hospitals to the community, then "community care" must be something more than a hollow catch phrase. If hostels . . . are to be the answer ... then there must be many more of them. The ever increasing number of cases remanded in custody for psychiatric report is evidence that the remand prisons are subserving the function of the former observation wards."

In the circumstances it seems wiser to accept the lack of alternative accommodation and consider how present mental hospitals could be upgraded to provide continuing and better care in the reorganised Health Service, rather than hope that they will eventually wither away. This hope seems to have relied too much on wishful thinking and too little on evidence. It would be more realistic to accept that chronic handicaps, including chronic mental illness, will continue and that in considering priorities in future it might be better to concentrate on improving needed facilities rather than using scarce resources on unproved but expensive areas of medicine.

The medical model that if people with mental illness were all treated in general hospitals they would get better is a myth. To assume that people with mental illness would get better if they were treated in general hospitals is obviously nonsense. Their prognosis depends, apart from other factors, on the quality of the staff and the resources available, and not on the type of hospital. Some mental illness is not curable, though all mentally ill patients can be helped to a limited extent with symptomatic treatment and management. Some illnesses produce lifetime incapacity. Mental hospitals provide asylum as well as treatment and look after people who may otherwise be neglected. Some people will require permanent care, help, and treatment, whether at home, in a community hostel or in hospital. If funds are short and there is no likelihood of expansion of community facilities this should be accepted in planning.
We thank Mr A V Swan of the department of community medicine, St Thomas's Hospital, for completing the analysis of the data. We also thank the nursing staff and social workers at Tooting Bec Hospital for the major part they played in carrying out the initial census and the secretarial staff of the drug dependence unit for doing the follow-up. Requests for reprints or for further information from this study and the questionnaire should be addressed to $\mathrm{Dr} T \mathrm{H}$ Bewley, Tooting Bec Hospital, London SW17 8BL.

\section{References}

1 Department of Health and Social Security, Hospital Services for the Mentally Ill, (HM(71) 97). London, DHSS, 1971.

2 Department of Health and Social Security, Services for Mental Illness related to Old Age, (HM(72) 71). London, DHSS, 1972.

3 Tooth, G C, and Brooke, E M, Lancet, 1961, 1, 710.

${ }^{4}$ Oldham, A J, British fournal of Psychiatry, 1969, 115, 465.

${ }^{5}$ Baker, A A, Lancet, 1969, 1, 1090.

${ }^{6}$ Norton, A, British Medical fournal, 1961, 2, 528.

${ }^{7}$ Baldwin, J A, and Hall, D J, British fournal of Preventive and Social Medicine, 1967, 21, 56.

${ }^{8}$ Hailey, A M, Psychological Medicine, 1971, 1, 128.

${ }^{9}$ Hailey, A M, British fournal of Preventive and Social Medicine, 1974, 28, 180.

${ }^{10}$ Cross, K W, Hassall, C, and Spencer, A M, British fournal of Preventive and Social Medicine, 1970, 24, 177.

${ }^{11}$ Mezey, A G, and Syed, I A, Lancet, 1972, 1, 251.

${ }^{12}$ Fryers, T, Psychological Medicine, 1974, 4, 196.

13 Letemendia, F J J, and Harris, A D, Lancet, 1973, 2, 1013.

${ }^{14}$ Registrar General, Statistical Review of England and Wales for the Year 1968, Appendix 4, English Life Table No 12 (1960-2). London, HMSO, 1970.

${ }^{15}$ DHSS Statistical and Research Report Series, No 8. London, HMSO, 1974.

${ }^{16}$ Rollin, H R, The mentally abnormal offender and the Law. Oxford, Pergamon Press, 1969.

\title{
Identification and definition of long-stay mental hospital population
}

\section{EAMONN FOTTRELL， RAFIC PEERMOHAMED， RAJNIKANT KOTHARI}

\section{Introduction}

With the plan to run down and eventually close the large mental hospitals in England and Wales and provide treatment in modern psychiatric units in general hospitals, ${ }^{1}$ what to do with the 60000 long-stay patients still in the mental hospitals remained a problem. We believe that within every population of long-stay psychiatric patients there is a group that presents special problems of rehabilitation and discharge. Furthermore, we believe that the existence of such "problem" groups is the main factor in maintaining the stability of long-stay populations in mental hospitals.

Our aim, therefore, was, firstly, to identify the problem group at Tooting Bec Hospital, and, secondly, to define its demographic and clinical characteristics, with the hope that the possibilities for rehabilitation would be enhanced.

\section{Present study}

\section{POPULATION}

Tooting Bec Hospital is a large mental hospital for psychiatric illnesses of all kinds except those in which the basic problem is subnormality of intelligence. During the period of study a total of 1292 inpatients were being treated. Physical and psychotherapeutic methods of treatment are used but the emphasis is on physical methods, such as psychotropic drugs and electric convulsion therapy. 
TABLE I-Length of stay in hospital of 1042 patients

\begin{tabular}{|c|c|c|c|c|c|c|c|c|c|c|c|c|c|c|c|c|c|c|c|c|c|c|c|c|c|c|c|c|c|c|}
\hline $\begin{array}{l}\text { Length of stay } \\
\text { (years) } \\
\text { No of patients }\end{array}$ & $\begin{array}{l}1- \\
160\end{array}$ & $\begin{array}{l}2- \\
100\end{array}$ & $\begin{array}{l}3- \\
87\end{array}$ & $\begin{array}{l}4- \\
67\end{array}$ & $\begin{array}{l}5- \\
78\end{array}$ & $\begin{array}{l}6- \\
51\end{array}$ & $\begin{array}{l}7- \\
43\end{array}$ & $\begin{array}{l}8- \\
31\end{array}$ & $\begin{array}{l}9- \\
40\end{array}$ & ${ }_{41}^{10-}$ & 11- & $\begin{array}{l}12- \\
39\end{array}$ & $\begin{array}{l}13- \\
26\end{array}$ & $\begin{array}{l}14- \\
25\end{array}$ & $\begin{array}{l}15- \\
25\end{array}$ & $\begin{array}{l}16- \\
15\end{array}$ & $\begin{array}{l}17- \\
25\end{array}$ & \begin{tabular}{|l|}
$18-$ \\
17
\end{tabular} & $\begin{array}{l}19- \\
21\end{array}$ & $\begin{array}{l}20- \\
37\end{array}$ & $21-$ & $-\frac{22-}{15}$ & 23- & 24- & $\begin{array}{c}25- \\
4\end{array}$ & $\begin{array}{c}26- \\
1\end{array}$ & $\mid \begin{array}{c}27- \\
0\end{array}$ & 28- & - $29-$ & $\mid \begin{array}{c}30- \\
0\end{array}$ \\
\hline
\end{tabular}

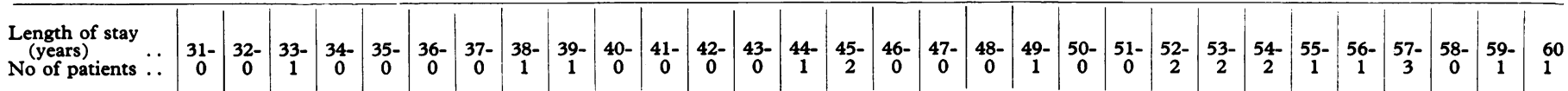

The hospital serves a population of 200000 , of whom 170000 are under the age of 65 . The number of patients admitted during the year April 1974 to March 1975 was 1184 . Most patients needing admission for psychiatric treatment in Britain are still treated in large mental hospitals similar to Tooting Bec Hospital.

\section{METHOD}

The study was divided into two parts.

Part 1-In the first part of the study the sister or charge nurse of every ward in the hospital returned to us both the name and the duration of stay of every patient in the ward who had been in hospital for a year or more. With this information we identified a group of patients who were characterised by being in hospital for a specific period of time and also by having a slow yearly decline in their numbers as compared with the rest of the long-stay population. We called them the "problem" group.

Part 2-In the second part of the study we compiled a questionnaire on the patients in the problem group and circulated it to their respective wards for completion by the ward sister or charge nurse. The questionnaire sought demographic age, sex (and social class), and clinical information. We made ourselves available to the nursing staff to help with completing the questionnaire. Most difficulties arose in allocating patients to particular diagnostic categories and in assessing their mental and physical states.

\section{DEFINITIONS}

Patients who were unmarried or whose spouse or cohabitee had died or who were separated or divorced were classed as single. Those with no known first-degree relatives were classed as not having relatives. Patients aged under 45 were classed as young, those aged $45-65$ as middle-aged, and those aged over 65 as old. Social class was based on the Registrar General's classification. ${ }^{2}$ Patients described by the staff as having been visited at least once in the previous three months were classed as often visited, those described as not having had a visit in the previous three months but who had had at least one visit in the preceding 12 months were classed as rarely visited, and those described as not having been visited in the previous 12 months were classed as never visited. Patients who did not leave the ward setting daily to attend an occupation were classed as "unoccupied," even though they helped with some tasks on the ward.

Psychiatric diagnosis was based on the eighth edition of the World Health Organisation's international classification of disease, the descriptions of the provisional World Health Organisation's glossary of mental disorders being used. Psychiatric state was classed as good when the patients were without psychiatric symptoms and would be fit to live in the community if there were no other factors of a social or physical nature militating against their discharge. Patients with conditions such as mild depressive or anxiety states, those with encapsulated delusions or mild paranoid states that did not upset their daily lives or activities, and patients whose mental state was well controlled by medication were regarded as being in a reasonably good mental state. Acutely disturbed patients with florid symptoms and patients with advanced organic and functional psychotic states were classed as being in a "poor mental state"; these patients received most psychiatric care and attention and were under continual observation.

Patients without evidence of physical illness or disability were classed as being in a "good physical state." Those with minor physical complaints or disabilities, such as mild degrees of arthritis, bronchitis, or minor residual incapacities due to cerebrovascular accidents, and those with a history of angina and coronary thrombosis or with diabetes mellitus or cardiac failure that had responded well to medication were all classed as being in a 'reasonably good physical state." There were no physical contraindications to these patients leaving the ward to attend work, occupational therapy, or recreation, and they needed little medical supervision and nursing. Patients with severe physical complaints, such as advanced heart failure, arthritis, or multiple sclerosis; bed-ridden, feeble patients of advanced age; and patients who had to be nursed in geriatric chairs due to various disorders affecting their balance and mobility were all classed as being in a "poor physical state." These patients received most medical and nursing care and were on many and varied forms of medication; most never left the ward except to be admitted to a general hospital or attend its outpatient department. Patients on night sedation were classed as being "on medication." Any patient in hospital for a year or more was classed as a long-stay patient. ${ }^{3-5}$

\section{Results}

PART I

The results of the first part of this study supported our hypothesis that there was a problem group of long-stay patients in the hospital. Table I shows the lengths of stay of 1042 patients; none had been in hospital for over 60 years. Between one and eight years the numbers declined steadily, and from eight to 23 years the numbers fluctuated, although there was a net decline. From then onwards the numbers again fell steadily with practically no fluctuation. The 28 patients who had been in hospital for 24 to 60 years (table I) were mostly elderly and frail. Their numbers were falling rapidly due to death rather than discharge. They were excluded from the problem group.

Altogether 422 patients ( $40 \%$ of the total) had been in hospital for eight to 23 years (table I). Though they showed a net decline in number (from 31 to 13 patients), this fall was slower than in the rest of the patients. They had been in hospital for a total of 6030 years compared with 3102 years for the rest of the patients. These 422 patients were regarded as the problem group.

\section{PART 2}

Table II gives the demographic and clinical characteristics of the patients in the problem group. Altogether $52 \%$ of the patients were over the age of 65 and $48 \%$ were either young or middle-aged at the time of admission. Nearly all had been admitted informally (over $99 \%$ ) and had few family or community contacts; $70 \%$ were single, and, although $69 \%$ had relatives, $57 \%$ were rarely or never visited. Seventy per cent came from social classes IV and V and were mainly unskilled, semi-skilled, or skilled manual workers. Some two-thirds were unoccupied throughout the day. Women outnumbered men by $54 \%$ to $46 \%$.

TABLE II-Demographic and clinical characteristics of 422 problem long-stay Dsychiatric patients

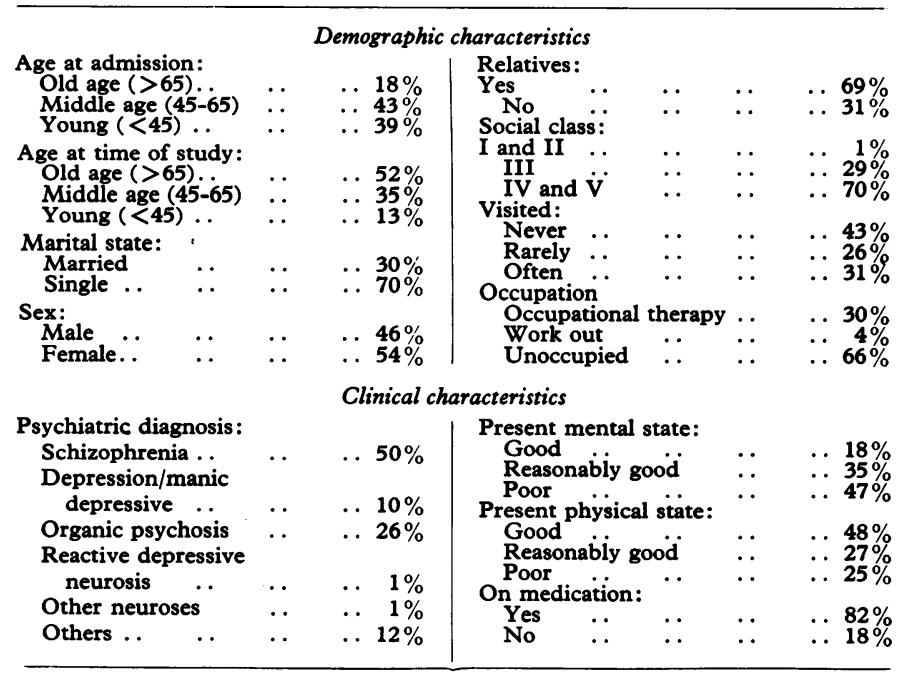

Half of the patients were suffering from schizophrenia and $26 \%$ from organic psychosis. Other psychiatric diagnoses such as alcohol addiction, personality disorders, and drug dependence accounted for $12 \%$. Severe depression (manic depressive type) was diagnosed in $10 \%$ of the group. Reactive depressive illness and other neurotic 
states were diagnosed in $2 \%$ of the patients. Eighteen per cent were in a good mental state, $35 \%$ were in a reasonably good mental state, and $47 \%$ were in a poor mental state. Forty-eight per cent of the patients were in a good physical state, $27 \%$ were in a reasonably good physical state, and $25 \%$ were in a poor physical state. Eighty-two per cent of the patients were on medication.

\section{Discussion}

Most research on long-stay psychiatric patients has been directed at either assessing the rate of accumulation of "new chronics" $4-7$ or studying the overall problem presented by old, long-stay populations and assessing their attrition rate. ${ }^{38-10}$ None, however, has sought to identify and define a "problem" group of long-stay patients. It is generally agreed that the number of long-stay patients in mental hospitals is declining: the debate concerns the rate of decline. Tooth and Brooke ${ }^{8}$ predicted that of all long-stay patients in 1954 none would remain by 1970 and that the rate of fall could be depicted arithmetically (linearly)

Lindsay ${ }^{11}$ argued that the rate should be depicted geometrically (curvilinearly), as did Baldwin and Hall. ${ }^{9}$ Our findings do not support the prediction of Tooth and Brooke, ${ }^{8}$ as we still had 73 patients who were long-stay patients in 1954 and were likely to have such patients for the foreseeable future.

There were obvious dangers and drawbacks in applying results derived from one mental hospital to other mental hospitals, and Tooting Bec Hospital has probably admitted more long-term patients than average over the years. Nevertheless, we are convinced that most, if not all, mental hospitals have a problem group of long-stay patients, the size of which will vary from hospital to hospital and will reflect not only the admission policies of those hospitals over many years but also many other factors operating within them and in the communities they serve, such as the facilities for treatment and rehabilitation and the availability of aftercare hostels and homes. It may be advisable for each mental hospital to assess the size of its problem group, which is relatively easy, as the first part of this study shows. Such local studies would have advantages over national studies, as they would indicate the local needs and facilitate planning on a local level to rehabilitate these patients.

The greatest obstacle to running down and eventually closing the mental hospitals is the existence of these problem groups. Indeed, this study shows that there is a rapid decline in the number of patients in hospital from one year up to eight years, probably as a result of discharge to the community, and also a rapid decline in the number of patients in hospital after 23 years, when death is probably more important in reducing the numbers than discharge. The problem group is the least influenced by discharge and death and remains relatively stable. The existence of problem groups helps to explain some of the discrepancies in the results of other studies. The characteristically slow rate of decline in the numbers of problem patients as compared with other long-stay patients helps to explain why the rate of decline in the numbers of long-stay patients as a whole tends to follow a curvilinear pattern ${ }^{9-11}$ rather than a linear pattern. ${ }^{8}$ Their existence also throws light on the findings of Baldwin and Hall, ${ }^{9}$ that in their sample of long-stay patients "a relatively short period was required to halve the population but a very long one to eliminate it."

We were encouraged by the finding that there may be scope for rehabilitating many of these patients, as many were in a good or reasonably good state of mental health $(53 \%)$ and physical health $(75 \%)$. In a previous study ${ }^{12} 40 \%$ of the non-feeble, long-stay psychiatric population as a whole were found to be potentially dischargeable if adequate aftercare facilities of a residential and supportive nature were available. There was, however, little encouragement in the report of the Department of Health, ${ }^{13}$ which showed that only seven premises were opened by local authorities in 1970 providing 107 places for the mentally ill, and that the total number of residents in houses and residential training centres owned by local health authorities throughout England and Wales was only 1584. Unless local authorities provide adequate accommodation and aftercare facilities for these patients (and in the present economic climate that is unlikely) they will remain in hospital for the rest of their lives. That may be preferable to discharging them into the care of relations or a community that is ill-prepared to receive them.

Finally, we believe that our study has identified an important and previously undescribed group of long-stay psychiatric patients, the identification of which increases our understanding of the dynamics of long-stay psychiatric groups as a whole. Methods must be fund for preventing the accumulation of problem long-stay patients, and studies are in progress at this hospital to identify predictive indices of psychiatric chronicity.

We are grateful to Dr Thomas Bewley, Tooting Bec Hospital, to Professor John Wing and Dr Sheila Mann, of the MRC Unit for Social Psychiatry, Institute of Psychiatry, London, and to Mrs Anthea Hailey and Dr Alan Norton for help and advice; to the nursing staff of Tooting Bec Hospital; and to Mrs E V Clay, Mrs J Dale, and Mrs S Jones for secretarial work.

\section{References}

${ }^{1}$ Department of Health and Social Security, Annual Report, 1970. London, HMSO, 1971.

2 General Register Office, Classification of Occupations, 1950. London, HMSO, 1951.

${ }^{3}$ Hailey, A M, Psychological Medicine, 1971, 1, 128.

${ }^{4}$ Measey L G and Smith H, British Fournal of Psychiatry, 1973, 123, 349.

${ }^{5}$ Hailey, A M, British Fournal of Preventive and Social Medicine, 1974, 28, 180.

${ }^{6}$ Magnus, R V, British Fournal of Psychiatry, 1967, 113, 555.

7 Mezey, A G, and Evans, E, British Fournal of Psychiatry, 1968, 114, 1399.

8 Tooth, G C, and Brooke, E M, Lancet, 1961, 1, 710.

9 Baldwin, J A, and Hall, D J, British Fournal of Preventive and Social Medicine, 1967, 21, 56

${ }^{10}$ Hailey, A M, British fournal of Preventive and Social Medicine, 1973, 27, 255.

11 Lindsay, J S B, Lancet, 1962, 1, 1354.

12 Fottrell, E, and Majumder, J L, Social Psychiatry, 1975, 10, 57.

13 Department of Health and Social Security, Hospital Services for the Mentally Ill. London, HMSO, 1971. 